\title{
Studies on intra-specific variations in the diamondback moth, Plutella xylostella (Lepidoptera: Yponomeutidae) under different geographical regions
}

\author{
Budhi Ram*, K. C. Sharma, Nisha Devi and V. G. S. Chandel \\ Department of Entomology, College of Horticulture, Dr YS Parmar University of Horticulture and Forestry, Nauni, \\ Solan- 173230 (Himachal Pradesh), INDIA \\ *Corresponding author. E-mail: brnegi.entomology@gmail.com
}

Received: January 01, 2016; Revised received: June 05, 2016; Accepted:August 24, 2016

Abstract: Studies on intraspecific variations in insect pests are an important tool for preparation of management strategy in different geographical regions. In this paper we tried to establish that these variations are also found in the diamondback moth $(P$. xylostella) populations under north Indian conditions with respect to reproductive biology. The pest populations were collected from five different geographical regions viz. Hisar (800feet), Kangra (2200feet), Solan (4200 feet), Theog (7500feet) and Kinnaur (9000feet) and then reared under laboratory conditions at $25 \pm 1^{\circ} \mathrm{C}$ on cauliflower. The life table analysis revealed that the female from the Kangra population laid maximum eggs (332.16 eggs/female) whereas the number of eggs laid by the female from the Hisar, Solan, Theog and Kinnaur population was 189.53, 207, 252 and 270 eggs/female, respectively. The doubling time (DT) was observed to be the lowest for Kangra (3.12 days) and maximum for the Hisar (4.59 days) population, whereas weekly multiplication rate was minimum for the Solan (2.252) and maximum for the kangra (4.73) population. The true generation time was the lowest for the Kangra (18.54 days) and highest for the Hisar (24.38 days) population. The true intrinsic rate of increase $\left(r_{m}\right)$ was found to be maximum ( 0.222 female progeny/female/day) for the Kangra whereas for the Kinnaur, Theog, Solan and Hisar population it was $0.203,0.202,0.182$ and 0.151 female progeny/female/day thereby indicating that the Kangra population is more prolific as compared to the population from other geographical regions. The results are indicative of geographical variations among different populations of $P$. xylostella.

Keywords: Diamondback moth, Intraspecific variation, Reproductive biology

\section{INTRODUCTION}

The diamondback moth, Plutella xylostella (L.) (Lepidoptera: Yponomeutidae) is a pest of crucifer crops. It was reported for the first time in India by Fletcher (1914). Now it has been noticed all over India where plants belonging to family Brassicaceae are grown (Devi et al., 2004). In India, its infestation leads to $30-100 \%$ loss of the cole crops (Ahmed et al., 2009). From Himachal Pradesh, Bhalla and Pawar (1977) reported this pest on cruciferous crops in temperate regions where cabbage and cauliflower are grown. Later on the pest was found as a regular and serious pest of cabbage and cauliflower (Anonymus, 1991 and Bharwal, 1997). The first instar larvae mine in the leaf and the subsequent instars feed on the leaf and skeletonize it ultimately affecting the plant growth and rendering it unfit for further use. Due to variations in various agroclimatic factors, this insect sometimes assumes the status of major pest and performs differently when fed on different host plants under different temperatures and climates and has different resistant levels to various insecticides. However, the variations of life-histories and life-table parameters of P. xylostella from different geographical regions when fed on the same host plant have not been well determined (Pan et al., 2014). The recognition of intra-specific variations, its nature and scope may aid our understanding of the pest and also to predict its spatial and temporal occurrence to devise effective management strategies and to characterize population responses to control measures (Khiban et al., 2010)

The aim of this study was to compare the differences in life tables among five populations of $P$. xylostella from different geographical regions in North India when reared on the same host plant (cauliflower) and at the same temperature. The findings will help to develop better management and control strategies against this pest.

\section{MATERIALS AND METHODS}

Sampling: Samples of $P$. xylostella were collected manually from farmers field from five different localities of different altitudes (Table 1). Each sample comprised of at least 40 larvae and 20 pupae. These were immediately placed in plastic jar $(20 \mathrm{~cm} \times 15 \mathrm{~cm})$, the top of which was covered with muslin cloth with leaves of cauliflower inside the container as food to the developing larvae. These were further reared under laboratory conditions as per the method of rearing of the test insect as described below. 
Raising of laboratory culture: Plutella xylostella larvae and pupae so collected from five different localities were reared in cages of size of $36 \times 34 \times 24 \mathrm{~cm}$ with glass pan on three sides. Fresh leaves of cauliflower with their petiole dipped in glass vials $(7 \mathrm{~cm} \mathrm{x}$ $1.5 \mathrm{~cm}$ ) were kept inside these cages. The adult thus emerged were fed with $10 \%$ sugar syrup and were provided with fresh cauliflower leaves for egg laying. The eggs thus obtained were used for the further studies. The culture of the test insect collected from each locality was maintained under laboratory conditions at room temperature $\left(25 \pm 1^{\circ} \mathrm{C}\right)$ throughout the period of study.

Geographical variations: Studies on variations among population of the diamondback moth collected from different geographical regions were carried out by studying the life fertility tables as per the details given below.

Reproduction and population growth: Eggs of the diamondback moth obtained after rearing the larvae and pupae of each locality under laboratory conditions were used for studying the life tables. The life tables were prepared as per the observations recorded on the duration of pre-oviposition period, post-oviposition periods adult longevity and age specific fecundity. The intrinsic rate of increase $\left(r_{m}\right)$, mean generation time $(T)$, finite rate increase $(\lambda)$, doubling time (DT) and net reproductive rate $\left(\mathrm{R}_{\mathrm{o}}\right)$ were calculated using method of Brich (1948) and elaborated by Howe (1953) and Carey (1993).

\section{RESULTS AND DISCUSSION}

Oviposition activity reveals differences among the population collected from different localities. The oviposition period was found to be significantly higher (13.30) in case of the Hisar population whereas it was the lowest (8.20) for the Theog population. The fecundity was observed maximum (332.16 eggs/female) in case of females from the Kangra ecotype and the minimum (189.53 eggs/female) fecundity was recorded for the Hisar population (Table 2).

These findings revealed that there were marked variations in the fecundity of the diamondback moth collected from different geographic regions. Various other workers have found such dissimilarities between different geographical populations of $P$. xylostella. Arvanitakis et al. (2002) found the difference in the fecundity of $P$. xylostella from seven different geographical regions of Africa of which five averaged a fecundity of 210 eggs per female wheareas, two poppultions showed lesser fecundity of 115 and 170 eggs per female. Variations in oviposition period of $P$. $x y$ lostella was also observed by Pichon et al.(2004) from different geographical regions of the world and obserevd the longest oviposition period in Uzbekistan (30 days) as compared to other populations where it varied from 15-20 days. Mahaparta et al. (2006) also reported similar results from three states in India. He observed higher fecundity from Tamilnadu (305 eggs per female) wheras, it was least for New Delhi population (268.5 eggs per female). Pan et al. (2014) investigated variations in biology of $P$. xylostella from five geographical regions of China. The oviposition period ranged from 10.47 to 17.18 days whereas, fecundity varied from 337.18-411.47 eggs per female.

Fertility tables: Fertility table summarizes the information on the biological performance of a species. The net reproductive rate for the Hisar, Kangra, Solan, Theog and Kinnaur populations of the diamondback moth was $39.74,90.22,35.76,44.30$ and 43.13 , respectively at $25^{\circ} \mathrm{C}$ on cauliflower. The true generation time (the mean period from birth of the parents to the birth of offspring) for the respective geographical regions was found to be $24.38,20.09,19.65,18.76$ and 18.54 days whereas the value of $r_{m}$ for the diamondback moth collected from these localities was $0.151,0.222,0.182,0.202$ and 0.203 (female progeny/female/day), while the finite rate of increase $(\lambda)$ was $1.16,1.25,1.19,1.22$ and 1.22 , respectively indicating a marked variations in the intrinsic

Table1. Sampling localities of P. xylostella.

\begin{tabular}{llc}
\hline Locality & State & Altitude (feet) \\
Hisar (Haryana) & Haryana & 800 \\
Jaach (Kangra) & Himachal Pradesh & 2200 \\
Chambaghat (Solan) & Himachal Pradesh & 4200 \\
Theog (Shimla) & Himachal Pradesh & 7500 \\
Kalpa (Kinnaur) & Himachal Pradesh & 9000 \\
\hline
\end{tabular}

Table 2. Comparative analysis of biological parameters of $P$. xylostella collected from five different geographical regions.

\begin{tabular}{|c|c|c|c|c|}
\hline \multirow[b]{2}{*}{ Localities } & \multicolumn{4}{|c|}{ Reproductive phases } \\
\hline & $\begin{array}{c}\text { Pre-oviposition } \\
\text { period (days) }\end{array}$ & $\begin{array}{c}\text { Oviposition } \\
\text { period (days) }\end{array}$ & $\begin{array}{c}\text { Post-oviposition } \\
\text { period (days) }\end{array}$ & Total no. of eggs/ female \\
\hline Hisar & $3.20 \pm 0.25^{\mathrm{a}}$ & $13.30 \pm 0.64^{\mathrm{a}}$ & $0.50 \pm 0.44^{\mathrm{ab}}$ & $189.53 \pm 1.31^{\mathrm{d}}$ \\
\hline Kangra & $1.60 \pm 0.15^{\mathrm{c}}$ & $9.80 \pm 0.61^{\mathrm{b}}$ & $1.20 \pm 0.37^{\mathrm{a}}$ & $332.16 \pm 4.34^{\mathrm{a}}$ \\
\hline Solan & $2.40 \pm 0.33^{\mathrm{b}}$ & $9.20 \pm 0.55^{\mathrm{bc}}$ & $0.40 \pm 0.22^{\mathrm{b}}$ & $207.00 \pm 2.88^{\mathrm{cd}}$ \\
\hline Theog & $1.20 \pm 0.13^{\mathrm{cd}}$ & $8.20 \pm 0.31^{\mathrm{c}}$ & $0.30 \pm 0.15^{\mathrm{b}}$ & $252.19 \pm 4.54^{\mathrm{bc}}$ \\
\hline Kinnaur & $1.00^{\mathrm{d}}$ & $8.3 \pm 0.51^{\mathrm{c}}$ & $0.50 \pm 0.21^{\mathrm{ab}}$ & $270.00 \pm 4.45^{\mathrm{b}}$ \\
\hline
\end{tabular}

Figures followed by same alphabet are significantly at par with each other 
Budhi Ram et al. / J. Appl. \& Nat. Sci. 8 (3): 1629 - 1633 (2016)

Table 3. Comparative fertility analysis of five different $P$. xylostella populations.

\begin{tabular}{|c|c|c|c|c|c|}
\hline \multirow[b]{2}{*}{ Fertility parameters } & \multicolumn{5}{|c|}{ Localities } \\
\hline & Hisar & Kangra & Solan & Theog & Kinnaur \\
\hline Gross reproductive rate $:\left(\sum\left(\mathrm{m}_{\mathrm{x}}\right)\right)$ & 98.54 & 189.33 & 107.58 & 136.18 & 151.23 \\
\hline Gross fecundity: $\left(\sum\left(\mathrm{M}_{\mathrm{x}}\right)\right)$ & 189.5 & 332.15 & 206.90 & 252.19 & 270.07 \\
\hline $\begin{array}{l}\text { Net reproductive rate(female eggs/female })\left(R_{0}\right):\left(\sum\right. \\
\left.\left(1_{x} m_{x}\right)\right)\end{array}$ & 39.74 & 90.22 & 35.76 & 44.30 & 43.13 \\
\hline $\begin{array}{l}\text { Approximate generation time }\left(\mathrm{T}_{\mathrm{c}}\right) \text { : } \\
\left(\sum\left(\mathrm{xl}_{\mathrm{x}} \mathrm{m}_{\mathrm{x}}\right) /\left(\mathrm{R}_{0}\right)(\text { days })\right.\end{array}$ & 25.00 & 20.43 & 20.05 & 18.78 & 18.87 \\
\hline $\begin{array}{l}\text { The innate capacity for increase }\left(r_{c}\right) \text { : } \\
\left(\log _{e} R_{0} / T_{c}\right)\end{array}$ & 0.147 & 0.220 & 0.178 & 0.201 & 0.200 \\
\hline Doubling time (DT): $\left(\log _{\mathrm{e}} 2 / \mathrm{r}_{\mathrm{m}}\right)$ (days) & 4.59 & 3.12 & 3.80 & 3.430 & 3.41 \\
\hline Intrinsic rate of natural increase (female/female/day) $\left(r_{m}\right)$ & 0.151 & 0.222 & 0.182 & 0.202 & 0.203 \\
\hline Weekly multiplication rate: $\left(\mathrm{e} 7 \mathrm{r}_{\mathrm{m}}\right)$ & 2.87 & 4.73 & 2.25 & 4.11 & 4.14 \\
\hline Finite rate of increase $(\lambda)$ : $\left(\right.$ Antilog $\left._{e} r_{m}\right)$ & 1.16 & 1.25 & 1.19 & 1.22 & 1.22 \\
\hline $\begin{array}{l}\text { Mean age gross fecundity (days): } \\
\left(\sum x M_{x} / M_{x}\right)\end{array}$ & 25.30 & 20.37 & 19.59 & 19.03 & 19.94 \\
\hline Mean age net fecundity: $\left(\sum x L_{x} M_{x} / \sum L_{x} M_{x}\right)$ & 24.99 & 20.12 & 19.79 & 18.80 & 18.60 \\
\hline Eggs/female/day: $\left(\sum \mathrm{L}_{\mathrm{x}} \mathrm{M}_{\mathrm{x}} / \sum \mathrm{L}_{\mathrm{x}}\right)$ & 10.77 & 27.66 & 15.20 & 24.34 & 22.26 \\
\hline True generation time $(\mathrm{T}):\left(\log \mathrm{R}_{\mathrm{o}} / \mathrm{r}_{\mathrm{m}}\right)$ (days) & 24.38 & 20.09 & 19.65 & 18.76 & 18.54 \\
\hline
\end{tabular}

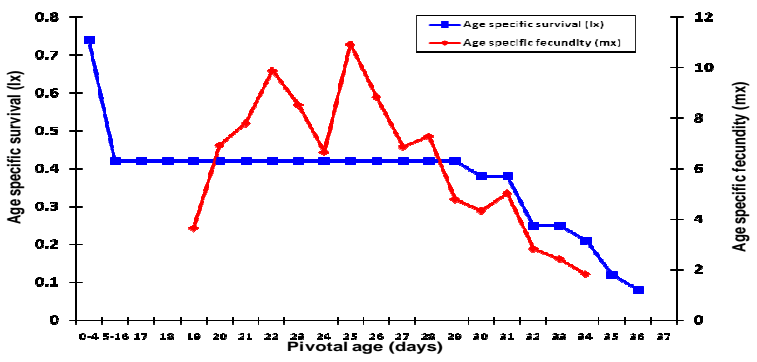

Fig .1. Daily age specific survival and age specific fecundity of $P$. xylostella for Hisar population.

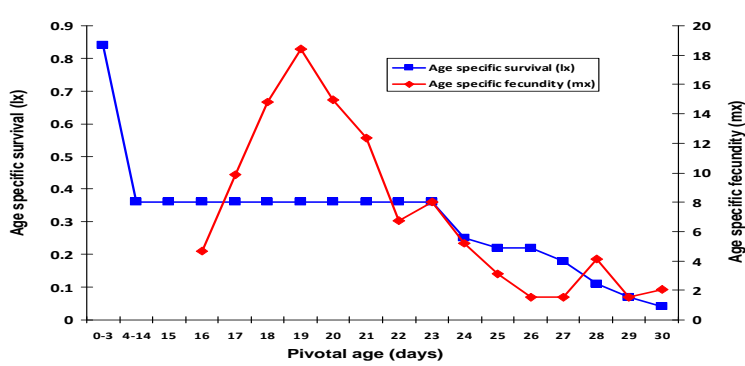

Fig. 3. daily age specific survival and age specific fecundity of $P$. xylostella Solan population.

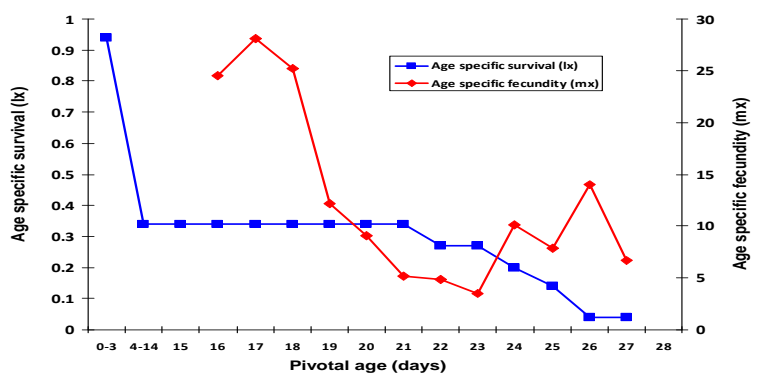

Fig. 5. daily age specific survival and age specific fecundity of P. xylostella Kinnau population.

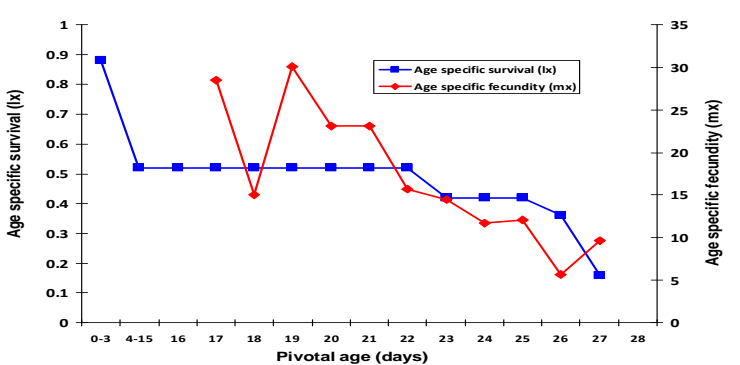

Fig. 2. Daily age specific survival and age specific fecundity of P. xylostella for Kangara population.

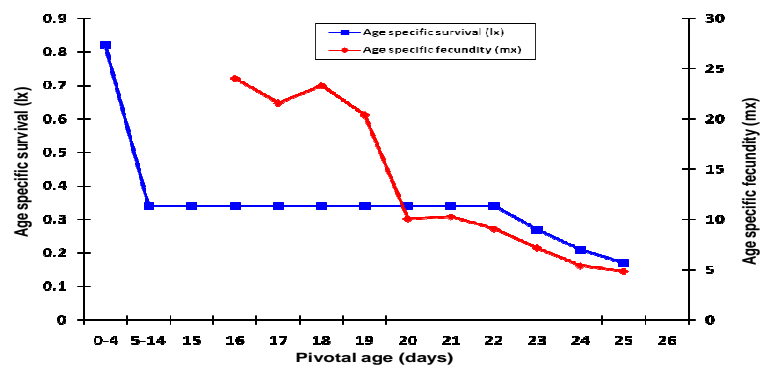

Fig. 4. Daily age specific survival and ag specific fecundity of plutella for Theog population.

rate of natural increase (Table 3). Since intrinsic rate of increase $\left(r_{m}\right)$ reflects many factors (such as fecundity, survival rate, and generation time) so these values would adequately summarize the physiological qualities of a species in relation to its capacity to increase. thus, it would be the most appropriate index to evaluate the performance of an insect from different regions (Southwood and Henderson 2009).

Our results support the studies carried out by Liu et al. (1985) who recorded differences in the intrinsic rate of increase $\left(\mathrm{r}_{\mathrm{m}}\right)$ in the population of the P. xylostella col- 
lected from three localities in Taiwan as $0.228,0.188$ and 0.151 females per day. Similar findings were observed by Sheng et al. (2002) for Diadromus collaris a parasitoid of the diamondback moth collected from two different localities in China. Pan et al. (2014) found variations in $\mathrm{r}_{\mathrm{m}}$ value of $P$. xylostella in China which were recorded the highest for Beijing population (0.2888) whereas it was the lowest for Shandong population (0.2165).

The present studies thus revealed variations among population from different geographical regions with respect to reproductive biology. Environmental variables are also important factors for local adaptation among allopatric regions, and biological divergence has been found along latitudinal gradients (Lee and Mitchell-Olds 2011). Variations among different populations of insects may also be attributed to geographical barriers between their habitats. Sometime distance alone can also function as a barrier to genetic exchange among populations (Ruggiero et al., 2004). As reported by Chu (1986) such variations might be due to migration of populations from different locations over long distances (>3000 km). Mayr and Ashlock (1991) reported the population differences due to geographic barriers that are defined as any terrain that prevents gene flow between populations. Schluter (2001) attributed that this variation due to adaptation of the different populations to their ecological niche.

\section{Conclusion}

On the basis of present studies it is concluded that there were significant variations with respect to reproductive biology among the populations of $P$. xylostella from different geographical regions. Besides, the difference in the true intrinsic rate of natural increase $\left(r_{m}\right)$ among the population collected from different geographical regions was also found, It was the highest for the Kangra population, indicating thereby that the diamondback moth for this geographical region is more prolific as compared to the population from other geographical regions

\section{REFERENCES}

Ahmed T, Ansari M and Ali H. (2009). Outbreak of diamondback moth, Plutella xylostella, in Aligarh, India. Trends in Bioscience 2(1): 10-12.

Anonymus. (1991). Integrated pest management studies on cauliflower and cabbage in temperate regions of Himachal Predesh. Final Report: ICAR Research Scheme, Department of Entomology, Dr. Yashwant Singh Parmar University of Horticulture and Forestry, Nauni-Solan (HP).

Arvanitakis L, Bonal F, Bordat A, Kirk A A and Bordat D. (2002). Biological and molecular variability within seven populations of Plutella xylostella (L.) from Benin. Improving Biocontrol of Plutella xylostella. In: Proceedings of the International Symposium of Montpellier, pp. 135-137.

Bhalla O P and and Pawar A D. (1977). A survey study of insect and non-insect pests of economic importance in Himachal Pradesh. Tiku and Tiku Kitab Mehal, Bombay. p. 80.

Bharwal R N. (1997). Pest management in temperate vegetable crops for vegetable and seed pupose, pp. 180-184. Summer school on : Summer hybrid and hybrid seed production technology of vegetables 7-26 April, held in division of vegetable crops, IARI, New Delhi

Brich S. 1948. The intrinsic rate of natural increase in insect population. Journal of Animal Ecology, 17: 15-26.

Carey J R. (1993). Applied demography for biologist with special emphasis on insects. Oxford University Press, New York.206 p.

Chu Y I. (1986). The migration of diamondback moth. In: Diamondback moth management(eds. N S Talekar and T D Griggs). Proceedings of the First International Workshop, 11-15 March 1985, Tainan, Taiwan, The Asian Vegetable Research and Development Center, Shanhua, Taiwan, AVRDC Publication No. 86-248. pp. 77-81.

Devi N, Bharadwaj V and Deshraj. (2004). Seasonal abundance of diamondbackmoth, Plutella xylostella(L.) and its natural enemies. Journal of Entomological Research, 28(4): 317-320.

Fletcher T B. (1914). Some south Indian insects. Superintendent, Government Press, Madras. 565p.

Howe R W. (1953). The rapid determination of intrinsic rate of increase of an insect population. Annals of Applied Biology, 40:134-155.

Khiaban N G M Z, Hejaz M S, Irani-Nejad K H, Mohammadi S A and Khaghaninia S. (2010). Genetic variability of geographical populations of the bollworm, Helicoverpa armigera Hübner (Lepidoptera: Noctuidae), in west and northwest of Iran. Munis Entomology and Zoology, 5(2): 670-676.

Lee CR and Mitchell O T (2011). Quantifying effects of environmental and geographical factors on patterns of genetic differentiation. Mol Ecol, 20:4631-4642.

Liu H, Chi H, Chen C N and Kung K S. 1985. The population parameter of the diamondback moth, Plutella xylostella on common kale. Plant Protection Bulletin of Taiwan, 27(2): 145-153.

Mayr E and Ashlock P D. (1991). Principle of systematic zoology. McGraw Hill.

Mohapatra P, Chack J and Narayanasamy P. (2006). Biological characteristics of certain diamondback moth ecdotypes. Journal of Entomology, 3(4): 277-280.

Pan QJ, Xiao LC, Lin L, Thomas J. Smith R and Liu TX. (2014). Geographical variations in life histories of Plutella xylostella in China. Journal of Pest Science, 87:659-670.

Pichon A, Bordat D, Bordat A, Arvanitakis L and Tertiios C. (2004). Biological and genetic differences between populations of diamondback moth from different geographic origins. In: The management of diamondback moth and other crucifer pests (eds N M Enderson and P M Ridland): Proceeding of the Forth International Workshop 26-29 November 2001, Melbourne, Victoria, Australia.

Ruggiero L F, Aubry K B, Buskirk S W, Koehler G M, Krebs C J, McKelvey K S and Squires J R. (2004). Ecology and conservation of lynxin the United States, general technical report RMRS-GTR-30 WWWFort Collins, cou.s.department of Agriculture, Forest service, Rocky mountain research station. 
Budhi Ram et al. / J. Appl. \& Nat. Sci. 8 (3): 1629 - 1633 (2016)

Schluter D. (2001). Ecology and the origin of species. Trends in Ecological. Evolution, 16: 391-399.

Shu Sheng L, Gebremeskel F B and Zuhua S. (2002). Reproductive compatibility and variation in survivaland sex ratio between two geographic populations of Diadromus collaris, a pupal parasitoid of the diamondback moth, Plutella xylostella. Bio Control, 47: 625-643.

Southwood TRE and Henderson PA (2009). Ecological methods, 3rd edn. Methuen, London. 